\title{
Examination of gaze behaviors under in situ and video simulation task constraints reveals differences in information pickup for perception and action
}

\author{
Matt Dicks \\ German Sport University Cologne, Cologne, Germany \\ Chris Button \\ University of Otago, Dunedin, New Zealand \\ AND \\ KeITH DAVIDS \\ Queensland University of Technology, Brisbane, Queensland, Australia
}

\begin{abstract}
Gaze and movement behaviors of association football goalkeepers were compared under two video simulation conditions (i.e., verbal and joystick movement responses) and three in situ conditions (i.e., verbal, simplified body movement, and interceptive response). The results showed that the goalkeepers spent more time fixating on information from the penalty kick taker's movements than ball location for all perceptual judgment conditions involving limited movement (i.e., verbal responses, joystick movement, and simplified body movement). In contrast, an equivalent amount of time was spent fixating on the penalty taker's relative motions and the ball location for the in situ interception condition, which required the goalkeepers to attempt to make penalty saves. The data suggest that gaze and movement behaviors function differently, depending on the experimental task constraints selected for empirical investigations. These findings highlight the need for research on perceptualmotor behaviors to be conducted in representative experimental conditions to allow appropriate generalization of conclusions to performance environments.
\end{abstract}

The design of appropriate empirical task constraints is a major issue in experimental psychology (e.g., Brunswik, 1956; Dhami, Hertwig, \& Hoffrage, 2004; Gibson, 1979; Hammond \& Stewart, 2001; Kareláia \& Hogarth, 2008). There is a concern that psychology has largely "neglected the environment" (Dunwoody, 2006, p. 139) in preference for simplified research designs that emphasize experimental control at the risk of jeopardizing generalizability of conclusions (Araújo, Davids, \& Passos, 2007; Dhami et al., 2004). Data from recent meta-analyses have revealed differences between laboratory studies and natural experimental settings for several measures of behavior, including perceptual expertise (Mann, Williams, Ward, \& Janelle, 2007) and human judgment heuristics (Hogarth \& Kareláia, 2007; Kareláia \& Hogarth, 2008). Such observations highlight the need to adequately sample environmental constraints in experimental designs to understand functional human behavior. This view has been expressed in a broad spectrum of research contexts, including motor coordination (Davids, Button, Araújo, Renshaw, \& Hristovski, 2006), judicial contexts (Brad- ford \& Goodman-Delahunty, 2008), marketing (Fasolo, Hertwig, Huber, \& Ludwig, 2009), and medical education (Wigton, 2008).

The importance of studying organism-environment relations was emphasized by Brunswik $(1955,1956)$ in a comprehensive methodological framework termed representative design. Brunswik (1956) stressed that experimental stimuli should be sampled from the organism's natural environment to be representative of the population of stimuli to which the organism has adapted and to which empiricists wish to generalize findings. Complementary to the view of Brunswik (1956; see Araújo et al., 2007; Dunwoody, 2006; Vicente, 2003), Gibson's (1979) theory of direct perception in ecological psychology was explicit on the importance of studying animal-environment relations while emphasizing the theoretical significance of a reciprocal relationship between perception and action (see also Michaels \& Carello, 1981; Warren, 2006). Gibson proposed that human behaviors are predicated on the perception of affordances (i.e., opportunities for action) offered by a set of environmental conditions relative to an

M. Dicks, m.dicks@dshs-koeln.de 
organism's bodily dimensions or action capabilities $(\mathrm{Ou}-$ dejans, Michaels, Bakker, \& Dolné, 1996; Warren, 1984).

The theories of Brunswik (1956) and Gibson (1979) underline the need to design experimental conditions in which representative stimuli are sampled from an organism's natural environment. A key implication is that experimental tasks should allow participants to produce unrestricted functional movement responses - behaviors that offer the opportunity to generate further prospective information (i.e., perception-action coupling; see Warren, 2006). This idea has significant implications for the study of human behaviors in everyday work and sports environments. Unfortunately, despite important methodological developments (e.g., Craig et al., 2009; Farrow \& Abernethy, 2003; Vickers, 1996), investigation of behaviors expressing perceptual expertise has been undermined by an overreliance on simplified laboratory methodologies (for a recent overview, see van der Kamp, Rivas, van Doorn, \& Savelsbergh, 2008). Previous researchers have proposed that expertise in sports is, in part, underpinned by an ability to anticipate the intentions of opponents from their kinematic actions (e.g., Huys, Smeeton, Hodges, Beek, \& Williams, 2008; Müller, Abernethy, \& Farrow, 2006). Data from gaze behavior (e.g., Savelsbergh, Williams, van der Kamp, \& Ward, 2002) and visual occlusion studies (e.g., Jackson, Warren, \& Abernethy, 2006) suggest that expert athletes exhibit different gaze strategies and are better at using advance visual information to anticipate an opponent's behaviors than are less skilled athletes. However, the equivocality of data in perceptual expertise studies has also been recently acknowledged (e.g., Vickers, 2007). Findings have indicated that expertise effects are exhibited more clearly under natural (in situ) experimental conditions than in ubiquitous video simulation laboratory settings (see Mann et al., 2007).

For example, Shim, Carlton, Chow, and Chae (2005) reported that expert tennis players coupled movement responses more accurately to information when facing a live opponent than when faced with artificial two-dimensional video and point-light simulation displays of an opponent (see also Farrow \& Abernethy, 2003). There is also some ambiguity in findings from pattern of gaze studies aimed at identifying the information sources fixated by athletes (for a review, see Vickers, 2007). Observations from videobased studies suggest that skilled goalkeepers' fixation locations differ from those of novices for the penalty kick, with regard to the time spent fixating the kicking and nonkicking legs of the penalty kick taker (Savelsbergh et al., 2002). Furthermore, comparison of skilled goalkeepers' patterns of gaze suggests that more successful performers directed gaze to the nonkicking leg of the penalty taker longer than did less successful participants (Savelsbergh, van der Kamp, Williams, \& Ward, 2005). In contrast, in studies under in situ conditions in which participants were required to perform requisite actions in response to an opponent and a projected ball, it was found that athletes' gaze behaviors were almost exclusively directed to the projectile before and during flight (e.g., McPherson \& Vickers, 2004; Panchuk \& Vickers, 2006).
In past work, Abernethy (1990) compared gaze behaviors of expert and novice squash players for in situ and video simulation conditions with performances measured using a verbal response. The results indicated similar gaze patterns for the two conditions, whereas squash playing expertise appeared to be independent of differences in search strategy. However, the use of a verbal response measure in both conditions implies that the participants fixated on information sources that supported their perceptual judgments, rather than the necessary information required to perform an interceptive response. In the present study, we aimed to address these current empirical shortcomings by comparing experienced association football goalkeepers' gaze behaviors for video simulation and natural experimental settings of the penalty kick. We focused on five experimental conditions that have all been utilized in previous perceptual expertise studies. The experimental protocols included two video conditions, in which the goalkeepers produced a verbal response (e.g., Abernethy, 1990; Farrow \& Abernethy, 2003) or a simulated joystick movement (e.g., Savelsbergh et al., 2005; Savelsbergh et al., 2002), and three in situ conditions, in which the goalkeepers produced a verbal response (Abernethy, 1990; Farrow \& Abernethy, 2003), a simplified body movement (e.g., Farrow \& Abernethy, 2003; Shim et al., 2005), or an actual interceptive movement response (e.g., McPherson \& Vickers, 2004; Panchuk \& Vickers, 2006). We tested the commonly held assumption that findings derived from existing video and in situ studies in which verbal and simulated movement measures are used generalize to in situ interception conditions. The objective was to ascertain whether such generalizations are valid.

Despite insights of Brunswik (1956) and Gibson (1979) suggesting how experimental methodologies may be improved, it remains surprising that studies of perceptual expertise still remain biased toward video simulation laboratory settings. For example, in three recently published perceptual expertise studies, two-dimensional video tasks were utilized, with participant responses measured with either a keypress or a written judgment (Cañal-Bruland \& Schmidt, 2009; Rowe, Horswill, Kronvall-Parkinson, Poulter, \& McKenna, 2009; Sebanz \& Shiffrar, 2009). Furthermore, an overview of methodological failings of the perceptual expertise literature with recommendations for future studies was recently provided by van der Kamp et al. (2008). They drew heavily on the ecological approach of Gibson (1979) and empirical findings from contemporary neuroscience that substantiated the complementary functioning of two neuroanatomically separate, but interconnected, streams within the visual cortex-a dorsal vision-for-action and a ventral vision-for-perception stream (Milner \& Goodale, 1995, 2008). The ventral stream is proposed to be responsible for perception of object information within the environment, whereas the dorsal stream is responsible for the visual control of goaldirected actions (Milner \& Goodale, 2008). The neuroanatomical distinction of Milner and Goodale (1995) implies that the laboratory task constraints in many existing per- 
ceptual expertise experiments, in which perception and action were decoupled (e.g., responding verbally to video footage), may have failed to harness the complementary function of the two cortical pathways, overemphasizing the role of the ventral pathway.

This distinction is nontrivial in the study of perceptual expertise in sports. Neo-Gibsonian empiricists (e.g., Michaels, 2000; van der Kamp, Oudejans, \& Savelsbergh, 2003; van Doorn, van der Kamp, \& Savelsbergh, 2007) proposed that, when studied in separation, the different functional demands of perception and action may predicate the pickup of different sources of visual information. Recently, van Doorn, van der Kamp, de Wit, and Savelsbergh (2009) used the Müller-Lyer illusion to compare gaze behaviors when participants were required to estimate the perceived length of a shaft or when participants were instructed to grasp the shaft. The results revealed differences in gaze behaviors for information detection under the differing perception estimation and action task constraints. When grasping the object, the participants spent more time fixating on the center of the shaft, whereas for the perceptual estimate condition, more gaze shifts were made to the two endpoints of the shaft. van Doorn et al. (2009) interpreted this finding as support for the view that the functional demands of perception and action constrain the differential pickup of allocentric and egocentric sources of information. Egocentric locations are held within a framework from the perspective of the perceiver, whereas allocentric locations are external to the perceiver and independent of his or her position (cf. Klatzky, 1998). Although the information held within egocentric and allocentric frameworks is not commonly specified (Klatzky, 1998), in this article we follow the distinction conveyed by van der Kamp et al. (2008) that the dorsal vision-for-action system requires egocentric information about properties of an object relative to the actor, whereas the ventral vision-for-perception system utilizes allocentric information associated with explicit awareness of the properties of objects in relation to other objects.

This distinction may provide a means to reconcile the differences observed in studies of gaze behaviors in laboratory and natural experimental conditions. Findings from video simulation studies in which perceptual judgment responses were measured underline the role of the ventral vision-for-perception system (van der Kamp et al., 2008) and may therefore emphasize understanding about the pickup of allocentric information external to the perceiver. In contrast, in situ studies in which participants were required to produce requisite actions in response to movements of an opponent and to ball flight may emphasize understanding about the pickup of egocentric information. That is, the data indicate that gaze is primarily directed to the projectile before and during flight (see Vickers, 2007). As the projectile is the goal of object interception, it is plausible that athletes need to fixate on this location for longer to pick up task-relevant information when actually required to produce an interceptive action response.

With these issues in mind, the aim of the present investigation was to compare gaze and movement behaviors of association football goalkeepers in response to the pen- alty kick. Verbal (e.g., Abernethy, 1990; Farrow \& Abernethy, 2003) and simulated movement (e.g., Farrow \& Abernethy, 2003; Savelsbergh et al., 2002) response conditions were measured under in situ and video conditions. As video settings do not present ball-flight stimuli, we were only able to measure performance for an interception response under an in situ condition (e.g., McPherson \& Vickers, 2004; Panchuk \& Vickers, 2006). Following previous research (e.g., Savelsbergh et al., 2005; Savelsbergh et al., 2002), we were interested in understanding whether information from the penalty taker's head, kicking leg, and nonkicking leg would comprise the most fixated gaze locations. Gaze behaviors of association football goalkeepers during the penalty kick have yet to be measured in situ. Following our theoretical analysis, it was expected that pattern of gaze would differ under in situ and video simulation constraints. It was predicted that ball location would be fixated for longer under in situ task constraints than would other information sources in order to provide participants with information that supports action (see McPherson \& Vickers, 2004; Panchuk \& Vickers, 2006; Vickers, 2007).

\section{METHOD}

\section{Participants}

Eight experienced association football goalkeepers, $22.8 \pm$ 4.1 years old, were recruited as participants from the New Zealand Southern Premier League, with a mean of $11.63 \pm 4.4$ years competitive association football experience as goalkeepers. One penalty taker, 24 years old, left-footed, was recruited to execute all kicks. The player was appropriately matched to the goalkeepers in performance standard and length of experience (cf. Panchuk \& Vickers, 2006). The goalkeepers had no prior experience of facing penalty kicks executed by the selected penalty taker.

\section{Apparatus}

Penalty kicks under all conditions were executed at a full-size goal $(7.32 \times 2.44 \mathrm{~m})$, represented by a white screen (Savelsbergh et al., 2002; van der Kamp, 2006), in the same indoor Astroturfcovered training facility. Following Savelsbergh et al. (2002), six target areas $(0.81 \times 1.50 \mathrm{~m})$ were marked on the screen as target reference's for the penalty taker (Figure 1). A regulation Size-5 soccer ball was used, and kicks were taken from a distance of $11 \mathrm{~m}$, as is stipulated by Fédération Internationale de Football Association (FIFA) laws. Ball-flight time was recorded using a pinhead microphone placed beside the ball to register the moment of football contact and a second microphone positioned next to the screen to register the point of ball impact with the goal. The continuous signals of both microphones were amplified and rectified before being fed into a bipolar comparator. The threshold for the bipolar comparator was set just above room noise.

Following previous research (e.g., Savelsbergh et al., 2005; Savelsbergh et al., 2002), goalkeeper-simulated movements were recorded using a handheld joystick (QuickShot Warrior 5 QS-123E). The joystick was positioned at waist height just in front of the participant. Each film clip in the video simulation was played through MATLAB (Version 7.6). The film clip start command synchronized the video footage with the joystick signal, which was then recorded in MATLAB using a USB data acquisition device (National Instruments 6008). Therefore, movement of the joystick was recorded immediately following the start of the film clip. For the in situ conditions, movements were recorded using an external high-speed $100-\mathrm{Hz}$ digital video camera (JVC GRDVL9800), placed $1.5 \mathrm{~m}$ horizontal to the penalty spot facing the goal. As the penalty taker's 


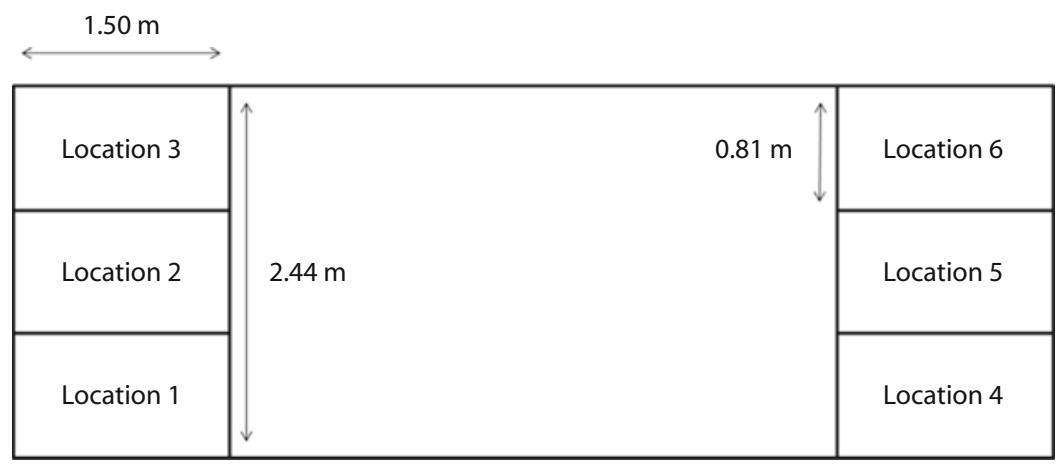

Figure 1. The goal divided into six locations for placement of penalties and response measures. From "Visual Search, Anticipation and Expertise in Soccer Goalkeepers," by G. J. P. Savelsbergh, A. M. Williams, J. van der Kamp, \& P. Ward, 2002, Journal of Sports Sciences, 20, p. 281. Copyright 2002 by Taylor \& Francis Group. Adapted with permission.

run-up began, the player moved through a timing gate (multichannel sports timer), breaking an infrared light beam, triggering a timer, and causing a bright white LED array to illuminate. A second timing gate was positioned immediately in front of the ball, so that the infrared beam was broken at the point of foot-ball contact as the ball moved forward. The ball movement triggered the timer to stop and the LED array to dim. The LED array was encased within a protective box and placed in view of the video camera to enable the precise measurement of the goalkeeper's movements relative to foot-ball contact. Goalkeeper movements were subjected to frame-by-frame analysis using SIMI Motion software Version 7 (SIMI Reality Motion Systems, Unterschleissheim, Germany).

\section{Measurement of Gaze Behaviors}

A mobile eyetracking system (Mobile Eye, ASL, Bedford, MA) was used to record gaze behaviors. The Mobile Eye is a headmounted, monocular eyetracking system that computes point of gaze within a scene through calculation of the vector (angle and distance) between the participant's pupil and cornea. The vector displacements were calibrated to a nine-point grid positioned within the scene for each experimental condition. A positional cursor highlighting the point of visual gaze was superimposed on the scene video by the Mobile Eye system with an accuracy of $\pm 1^{\circ}$ of visual angle and a precision of $0.5^{\circ}$ (the diameter of the cursor center was $2^{\circ}$ ). The video is relayed from the Mobile Eye head-mounted unit to a remote-mounted unit attached onto a modified digital video cassette recorder (DVCR; Sony GV-D1000E). During calibration, the scene video was viewed in real time for all conditions, because the DVCR was linked via firewire cable to a laptop (Dell Inspiron 6400), installed with EyeVision software. The participants were instructed to hold their head stable and to move their eyes only during calibration, after which calibration accuracy was checked by asking the participants to fixate on different objects in the task environment. Gaze behavior data were collected at a rate of 25 frames per second and subjected to a frame-by-frame analysis following testing using Focus X2 (Elite Sports Analysis, Fife, Scotland).

For the video simulation conditions, gaze behaviors were recorded in real time. Therefore, calibration accuracy was monitored at all times by an experimenter. For the in situ conditions, the DVCR was disconnected from the laptop following calibration and worn by the participants in a tight-fitting pack around their waist. This protocol ensured that the scene was recorded and captured for offline analysis in all in situ trials. During testing, calibration checks were carried out by instructing the participants to look at specific locations in their visual field and to verbalize where they were looking between each trial. In the event that the calibration appeared to drift between trials during offline analysis, the Mobile Eye "Shift Calibration" function permitted a uniform adjustment of the gaze calibration. Supplementary to the recorded file, the Mobile Eye was reconnected to the laptop after 10 trials of the in situ verbal and simulated movement response conditions to check calibration accuracy in real time. Pilot testing indicated that there was an increased risk of compromising the accuracy of calibration because of the goalkeepers' diving actions, so calibration accuracy was checked in real time after every 4 trials during the in situ inter-

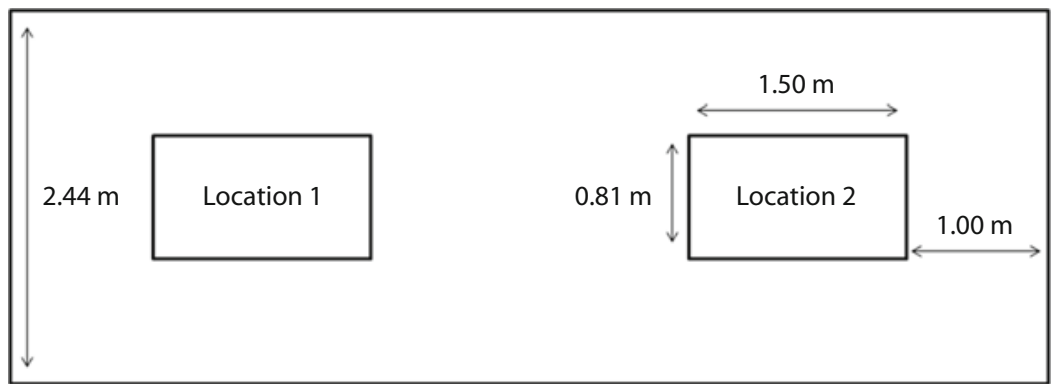

Figure 2. The goal divided into two locations for placement of penalties. From "A Field Simulation Study of the Effectiveness of Penalty Kick Strategies in Soccer: Late Alterations of Kick Direction Increase Errors and Reduce Accuracy," by J. van der Kamp, 2006, Journal of Sports Sciences, 24, p. 470. Copyright 2006 by Taylor \& Francis Group. Adapted with permission. 
ception condition. Additional calibration checks were carried out if the participants felt that the Mobile Eye had moved at any stage during the testing protocol.

For the in situ interception condition, there was concern regarding the increased risk of the ball ricocheting and causing damage to the Mobile Eye or injury to the participants. Thus, for the sake of participant safety, the penalty taker was instructed to aim penalties to two goal locations (Figure 2), equivalent to those studied by van der Kamp (2006), rather than the bottom corners of the goal. Although slightly different from those of the other conditions, the kick locations remained representative of those recorded for world-class performance (Morya, Bigatão, Lees, \& Ranvaud, 2005) and did not jeopardize comparison of gaze with the verbal and simulated movement conditions (see Oudejans et al., 1996). Risk of injury to the participants was further reduced by using cushioned mats to soften their landings when they dove in response to the kicks.

Following calibration in the in situ interception condition, the goalkeepers performed dives onto the cushioned mats while wearing the Mobile Eye without having to save kicks. A final calibration check with the Mobile Eye attached to the laptop was then performed before commencing the experimental trials. None of the participants reported any detrimental effects of wearing the Mobile Eye on performance.

\section{Procedure}

The goalkeepers faced penalty kicks in five different experimental conditions: video simulation verbal (VSV), video simulation movement (VSM), in situ verbal (ISV), in situ movement (ISM), and in situ interception (ISI). For the VSV and ISV conditions, the goalkeepers were instructed to verbally judge penalty kick direction without making any movements (e.g., Abernethy, 1990; Farrow \& Abernethy, 2003). Interestingly, pilot testing revealed that the goalkeepers tended to move toward the predicted kick direction, despite instruction to stand still and to only respond verbally. Therefore, we used a customized chinrest to restrict the participants' movement (Singer, Cauraugh, Chen, Steinberg, \& Frehlich, 1996). In the VSM condition, the participants were required to respond by moving a joystick (i.e., Savelsbergh et al., 2005; Savelsbergh et al., 2002), and in the ISM condition, the goalkeepers were required to produce a simplified body movement - a side step with their arms directed toward the anticipated goal location (e.g., Farrow \& Abernethy, 2003; Shim et al., 2005). For the ISI condition, the goalkeepers were instructed to perform as they would normally in a game, with no other constraints placed on performance (cf. Panchuk \& Vickers, 2006).

In the video conditions, the goalkeepers viewed the footage, as is described below. For the in situ trials, the goalkeepers faced penalties in real time against the penalty taker, orienting themselves centrally in the goal (3.66 $\mathrm{m}$ from either post) prior to each kick. The goalkeepers could respond to one of six possible locations for the verbal (i.e., VSV and ISV) and movement (i.e., VSM and ISM) response conditions (Savelsbergh et al., 2005; Savelsbergh et al., 2002). The six locations corresponded to the top, middle, and bottom of each side of the goal (Figure 1). In all four of these experimental conditions, the goalkeepers were given instructions based on those used in previous perceptual expertise studies (i.e., Savelsbergh et al., 2002; Shim et al., 2005). That is, the participants were instructed to judge the outcome of the penalty kick as quickly as possible, as in competitive performance, and to move to the predicted location as if to save the kick.

The penalty taker followed a test script, which included information about where to aim each kick in the goal. The player initiated the run-up at an approach angle of between $10^{\circ}$ and $30^{\circ}, 4.0 \mathrm{~m}$ from ball contact for each trial (Williams \& Griffiths, 2002), and used a nondeceptive penalty strategy. Recently, Schorer, Baker, Fath, and Jaitner (2007) demonstrated that the functional variability in movement coordination increases when executing deceptive actions. Moreover, it is currently unknown how the deceptive and nondeceptive actions of an opponent affect athletes' gaze behaviors, and researchers examining the effect of deception on perceptual expertise have thus far reported unequivocal findings (for contrasting results, see Jackson et al., 2006; Rowe et al., 2009). An examination of the effects of penalty taker deceptive intent and goalkeeping performance is beyond the scope of the present study. The penalty taker was instructed to use a nondeceptive strategy in order to minimize any variability in his kicking action within and between conditions.

The penalty taker's mean run-up and ball-flight times across each condition are presented in Table 1. The run-up approach times did not differ significantly among conditions $\left[\chi^{2}(4)=6.05, p=.195\right]$. Despite a significant main effect for condition on ball velocity $\left[\chi^{2}(4)=\right.$ $13.19, p<.01]$, Wilcoxon tests with a Bonferroni-corrected statistical significance level of .005 revealed no significant differences among conditions. Furthermore, the range of observed mean ball-flight times (i.e., 580-597 $\mathrm{msec}$ ) were representative of those of comparably skilled performers (for a review, see Kellis \& Katis, 2007). Collectively, these findings indicate a representative and acceptable level of control between experimental conditions (see Müller et al., 2009).

Prior to testing, the goalkeepers performed six familiarization trials for each condition. Goalkeeping performance was analyzed for 15 trials in each condition, with kicks directed toward the bottom corners of the goal ( 8 to the right and 7 to the left). The participants faced 5 additional trials with kicks distributed to varying goal locations for each condition, with the aim of masking awareness of the task procedure. Specifically, these locations consisted of the center of the goal followed by 1 trial to each of the remaining targets marked on the goal (Figure 1). The goalkeepers each performed in all 5 conditions in a random order, with performance assessed across 75 trials each. We only tested 1 goalkeeper per day in order to eliminate the risk of fatigue. In addition, the penalty taker had the opportunity to rest during and between experimental conditions whenever the eyetracker calibration was being checked. The spatial location of the penalties was randomized for each condition but presented in the same order for each participant. No augmented feedback was provided about performance.

\section{Video}

The video simulation footage for both video conditions was recorded prior to data collection. Filming took place at the same indoor Astroturf-covered facility as that in the in situ conditions. The footage was recorded using a $50-\mathrm{Hz}$ digital video camera (Canon MVX200i), which was positioned in the middle of the goal at a

Table 1

Mean Run-Up and Ball-Flight Times (in Milliseconds) Across Experimental Conditions

\begin{tabular}{|c|c|c|c|c|c|c|c|c|c|c|}
\hline & \multicolumn{10}{|c|}{ Condition } \\
\hline & \multicolumn{2}{|c|}{ VSV } & \multicolumn{2}{|c|}{ VSM } & \multicolumn{2}{|c|}{ ISV } & \multicolumn{2}{|c|}{ ISM } & \multicolumn{2}{|c|}{ ISI } \\
\hline & $M$ & $S D$ & $M$ & $S D$ & $M$ & $S D$ & $M$ & $S D$ & $M$ & $S D$ \\
\hline Run-up time & 1,417 & 73 & 1,403 & 75 & 1,388 & 107 & 1,385 & 94 & 1,402 & 80 \\
\hline Ball-flight time & 583 & 54 & 580 & 31 & 590 & 39 & 597 & 58 & 585 & 53 \\
\hline
\end{tabular}

Note-VSV, video simulation verbal; VSM, video simulation movement; ISV, in situ verbal; ISM, in situ movement; ISI, in situ interception. 
height of $1.60 \mathrm{~m}$. Each test film for the VSV and VSM conditions consisted of a total of 20 different kicks, consistent with the in situ conditions (see the Procedure section). Each film clip included the penalty taker's run-up, kicking action, and the initial portion of ball flight (Savelsbergh et al., 2002). The film clips were projected (Panasonic PT-LB20NTEA) onto a large screen $(2.4 \times 1.5 \mathrm{~m})$ positioned $4.3 \mathrm{~m}$ from the participant. The image of the penalty taker at ball contact was set at $0.72 \mathrm{~m}$ to ensure that it subtended a visual angle of $10.6^{\circ}$, thereby replicating the height of the penalty taker at ball contact for the in situ condition.

\section{Dependent Measures}

\section{Goalkeeping Performance}

Two dependent variables were used to assess timing and accuracy of goalkeeping performance: the mean number of penalty kicks saved and the mean moment of response initiation. In the noninterception conditions (VSV, VSM, ISV, and ISM), a save was recorded when the verbal/simulated response was at the correct location at the moment the ball crossed the goal line (Savelsbergh et al., 2002). The mean number of penalty kicks saved was submitted to an ANOVA (condition: VSV, VSM, ISV, ISM, ISI) with repeated measures. Post hoc comparisons were conducted using the Bonferroni correction procedure. The moment of response initiation was recorded for conditions in which the goalkeepers were required to produce a movement response (i.e., VSM, ISM, and ISI). Time of response initiation was denoted as the first observable movement (e.g., side step or movement of the joystick) made by the goalkeeper relative to the moment of foot-ball contact by the penalty taker. If the moment of response initiation occurred before ball contact, a negative value was recorded. If initiation occurred after ball contact, a positive value was recorded. Code-recode reliability ranged between $r=$ .98 and $r=1.0$ for the same experimenter and between $r=.87$ and $r=1.0$ for the two coders. The mean moment of response initiation was submitted to Friedman's ANOVA (condition: VSM, ISM, ISI) with repeated measures. Post hoc comparisons were conducted with Wilcoxon signed-ranks tests with a Bonferroni correction procedure.

\section{Gaze Behaviors}

Comparison of gaze behaviors for in situ and video simulation tasks is acknowledged to be challenging, given complications in reliably identifying moments of beginning and endpoints of trials that are common to all conditions (see Abernethy, 1990). In the present study, trial initiation time included the run-up and a portion of the penalty taker's preparation time to provide sufficient duration before penalty kick initiation (cf. Panchuk \& Vickers, 2006). The longest run-up approach times for each condition were 1,560 (VSV), 1,600 (ISV), 1,560 (VSM), 1,570 (ISM), and 1,540 $\mathrm{msec}$ (ISI). The onset of each trial was preset at $2,000 \mathrm{msec}$ prior to foot-ball contact. Trial endpoints for VSV, VSM, ISV, and ISM conditions were defined as the last appearance of the football in the Mobile Eye scene camera after the moment of penalty taker foot-ball contact. This value was $120 \mathrm{msec}$ for both of the video simulation conditions (i.e., the termination of the film display), whereas the mean trial endpoint was $370 \mathrm{msec}$ for ISV trials and $460 \mathrm{msec}$ for ISM trials. Trial endpoint for the ISI condition was defined as the moment at which the ball contacted the goalkeeper in saves or the screen in goals. The mean trial endpoint for ISI was $580 \mathrm{msec}$. Therefore, the trial endpoint used to compare gaze across all conditions was set at $120 \mathrm{msec}$, since data were available for all trials in all conditions for this duration post foot-ball contact.

Search rate. Three search rate measures were calculated: the mean number of fixations, the mean number of areas fixated on, and the mean fixation duration for each trial (Williams, Ward, Knowles, \& Smeeton, 2002). Fixation/tracking behavior was coded when gaze remained within $3^{\circ}$ of visual angle of a location or moving object for a minimum duration of three frames or $120 \mathrm{msec}$ (Panchuk \& Vickers, 2006). A saccade was coded when gaze location deviated from one information location to another for a minimum duration of two frames of video or $80 \mathrm{msec}$. Finally, a blink was recorded when the gaze cursor disappeared for a minimum of three frames of video or $120 \mathrm{msec}$. Randomly selected trials $(n=8)$ were recoded by the same experimenter and a second researcher in order to assess the reliability of the pattern of gaze data. Code-recode reliability ranged between $r=.98$ and $r=1.0$ for the same experimenter and between $r=.899$ and $r=.937$ for the two coders.

Despite the procedural steps taken to preserve accuracy of eye movement data, gaze calibration failed for the same 2 participants in the VSV and VSM conditions, because the lighting settings required for the video projection restricted these participants' pupil size to the extent that a consistently clear signal was not available throughout data collection. Visual search behaviors were also unavailable for 1 participant in the ISI condition because of an error in the orientation of the scene camera. There were no calibration difficulties for any of the other participants. A commonly used statistical method that deals with unbalanced datasets, frequently encountered in eye movement studies (e.g., see Baayen, Davidson, \& Bates, 2008; Kliegl, Risse, \& Laubrock, 2007), is the mixed-effect statistical model (for tutorials, see Bagiella, Sloan, \& Heitjan, 2000; Burton, Gurrin, \& Sly, 1998). In the present study, a mixed model was considered advantageous because it provides a more flexible method of dealing with missing data (cf. Baayen et al., 2008), as well as accounting for any variability in a participant's performance across repeated conditions (cf. Dixon, 2008). Each search rate dependent measure was analyzed using a mixed-model ANOVA with experimental condition as a fixed effect (VSV, VSM, ISV, ISM, ISI), participants as a random effect $(n=8)$, and a compound symmetry correlation structure (Burton et al., 1998; Van Dongen, Caldwell, \& Caldwell, 2006). Post hoc comparisons were conducted using the Bonferroni correction procedure.

Percentage viewing time. Ten locations were used to categorize position of gaze: the penalty taker's head, upper body (including arms), upper kicking leg and hip, upper nonkicking leg and hip, kicking leg (including foot), nonkicking leg (including foot), the turf between the player and the ball, the ball, the turf in front of the ball, and "other." The "other" category was used when gaze could not be coded because of extraneous jarring movements by the participant or when gaze was directed outside of the fixation location categories. The individual mean values of the percentage of time that gaze was directed to each of the 10 locations were submitted to a multivariate 5 (condition: VSV, VSM, ISV, ISM, ISI) $\times 4$ (moment of run-up: $2,000-1,501,1,500-1,001,1,000-501,500-0+120 \mathrm{msec}$ after ball contact) ANOVA with repeated measures on both factors. Since the percentage viewing time measures comprised a large data set, Tukey post hoc tests were used to follow-up significant effects in order to control the Type I error rate (Field, 2009).

\section{RESULTS}

\section{Goalkeeping Performance}

Mean performance scores observed for each condition for the number of penalty saves and moment of response initiation are presented in Table 2. There was a significant main effect of condition for the number of saves $[F(4,16)=6.062, p<.01]$. Performance was significantly better in the ISM $(M=13.00, S E=0.73)$ and ISI $(M=14.25, S E=0.31)$ conditions than in the VSV $(M=9.43, S E=1.00)$ and $\operatorname{VSM}(M=9.57, S E=0.65)$ conditions.

There was a significant main effect of condition on moment of response initiation $\left[\chi^{2}(2)=7.143, p<.05\right]$, 
Table 2

Dependent Measures Recorded for the Visual Anticipation Test Across Experimental Conditions

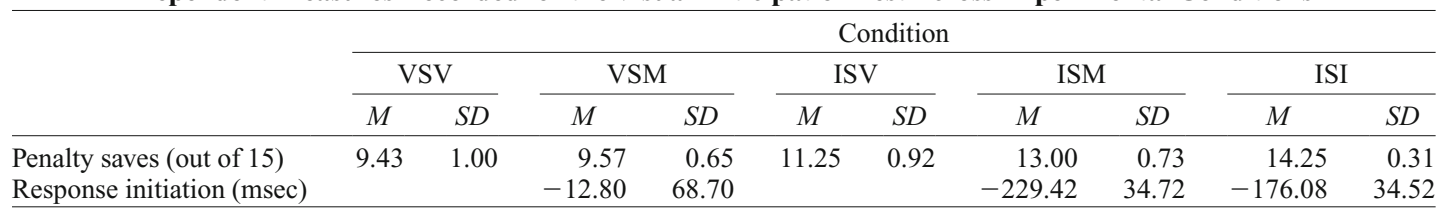

Note-VSV, video simulation verbal; VSM, video simulation movement; ISV, in situ verbal; ISM, in situ movement; ISI, in situ interception.

although follow-up Wilcoxon tests with a Bonferronicorrected statistical significance level of .167 revealed no significant differences among conditions. There was a trend for the goalkeepers to move earlier in the ISM condition than in the ISI and VSM conditions, whereas the goalkeepers tended to wait longer before movement initiation in the VSM condition than in the in situ conditions.

\section{Gaze Behaviors}

Search rate. Mean experimental condition values across the search rate measures are presented in Figure 3. There were significant main effects of condition for fixation duration $[F(4,23)=3.117, p<.05]$ and for number of fixation locations $[F(4,23)=4.218, p<.01]$. Post hoc tests indicated a longer fixation duration in the ISV condition $(M=581.32, S E=62.51)$ than in the ISM condition $(M=482.40, S E=34.65)$. Post hoc tests indicated that goalkeepers fixated on significantly fewer locations in the ISI $(M=2.94, S E=0.24)$ condition than in the $\operatorname{VSV}(M=3.51, S E=0.20)$ and $\operatorname{VSM}(M=3.49, S E=$ $0.13)$ conditions. There was no significant main effect of condition on the number of fixations $[F(4,23)=2.404$, $p=.08]$.
Percentage viewing time. Figures 4, 5, and 6 illustrate the effect of condition on participants' pattern of gaze. Figure 4 summarizes the most common fixation locations (i.e., the mode fixation location of all trials at each time code) for each condition at each phase of the penalty taker's run-up. The circles represent fixations: The larger the circle, the greater the frequency of fixations on that location. For clarity, the circles are accompanied by a letter ("A" denotes the mode, with descending frequency of fixations represented by subsequent letters). In all conditions, gaze was most commonly directed to the head or torso during the first $500 \mathrm{msec}$ of the penalty taker's approach to the ball, after which, distinct differences emerged between conditions. The most pronounced difference was the frequency of gaze allocation toward the ball in the ISI condition in comparison with all other experimental task constraints. The goalkeepers did not commonly fixate on the ball until the final $500 \mathrm{msec}$ of the penalty taker's approach in the VSV, VSM, and ISV conditions. The goalkeepers fixated on the ball as early as the first $500 \mathrm{msec}$ of the approach in the ISI condition, with frequency of gaze changes toward this location increasing considerably over the course of the penalty taker's run-up. Although the goalkeepers fixated on the ball as early as

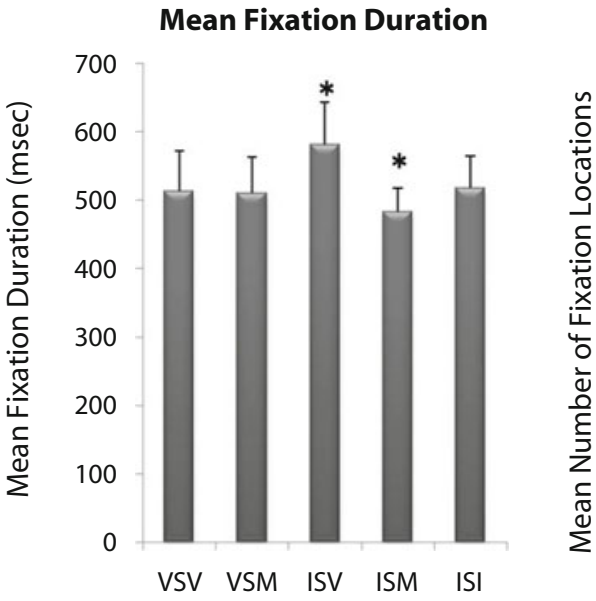

Condition
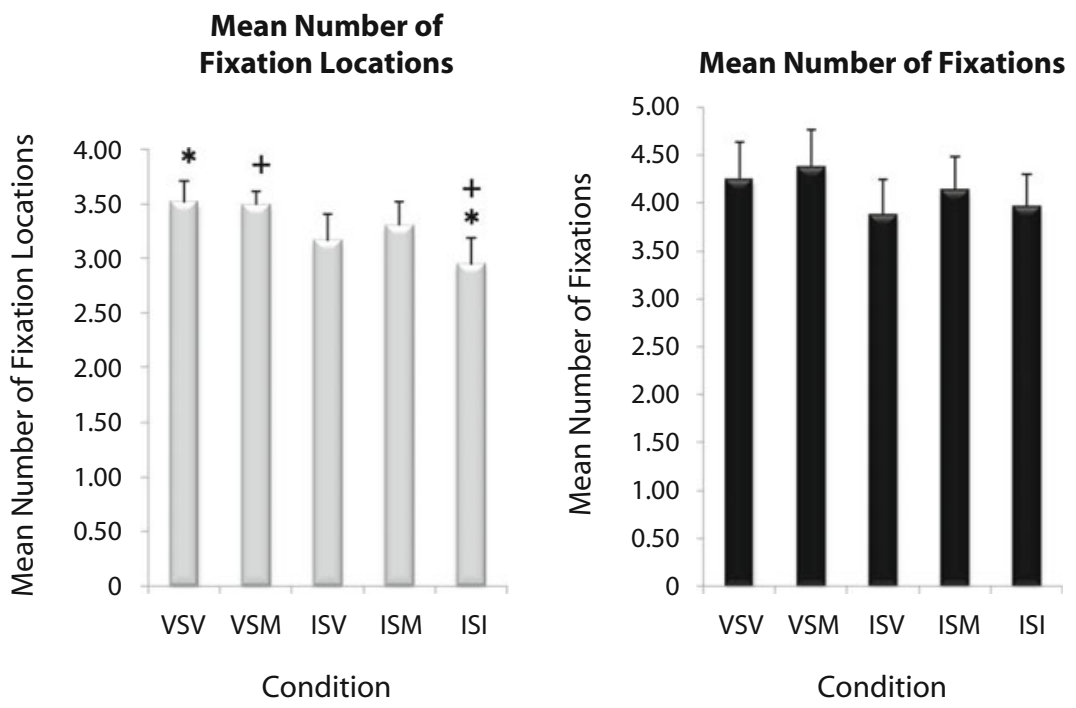

Figure 3. Mean fixation duration, number of fixation locations, and number of fixations across conditions. The vertical bars indicate the standard errors of the means. VSV, video stimulation verbal; VSM, video simulation movement; ISV, in situ verbal; ISM, in situ movement; ISI, in situ interception. Left panel: ${ }^{*}$ Post hoc difference between ISV and ISM, $p<.05$. Middle panel: ${ }^{*}$ Post hoc difference between VSV and ISI, $p<.05 ;{ }^{+}$post hoc difference between VSM and ISI, $p<.05$. 

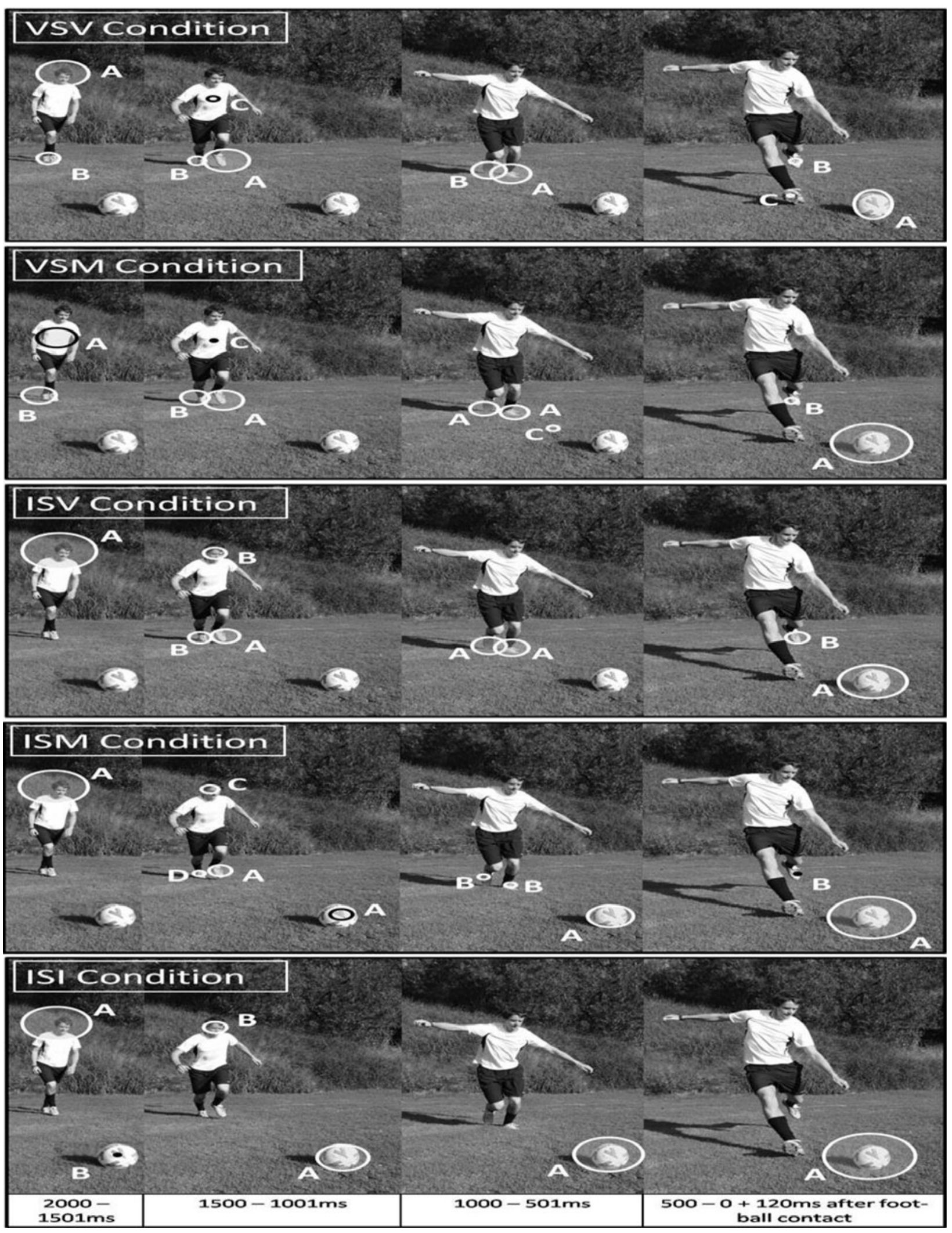

Figure 4. The most common fixation locations (i.e., the mode fixation location of all trials at each time code) for each condition at each phase of the penalty kick. The circles represent fixations: The larger the circle, the greater the frequency of fixations at that location. For clarity, the circles are accompanied by a letter (" $A$ " denotes the mode, with descending frequency of fixations represented by subsequent letters). VSV, video simulation verbal; VSM, video simulation movement; ISV, in situ verbal; ISM, in situ movement; ISI, in situ interception. 


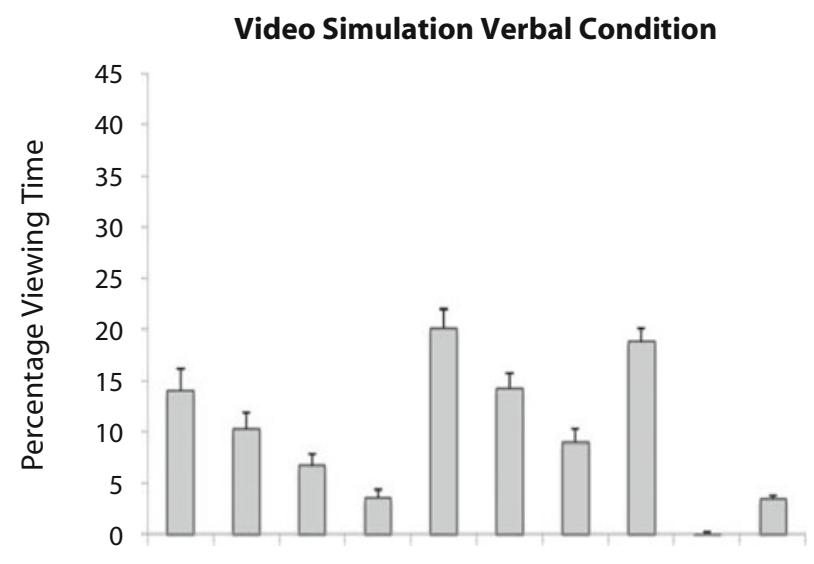

Head Torso UKL UNKL LKL LNKL F-B Ball Turf Other Location

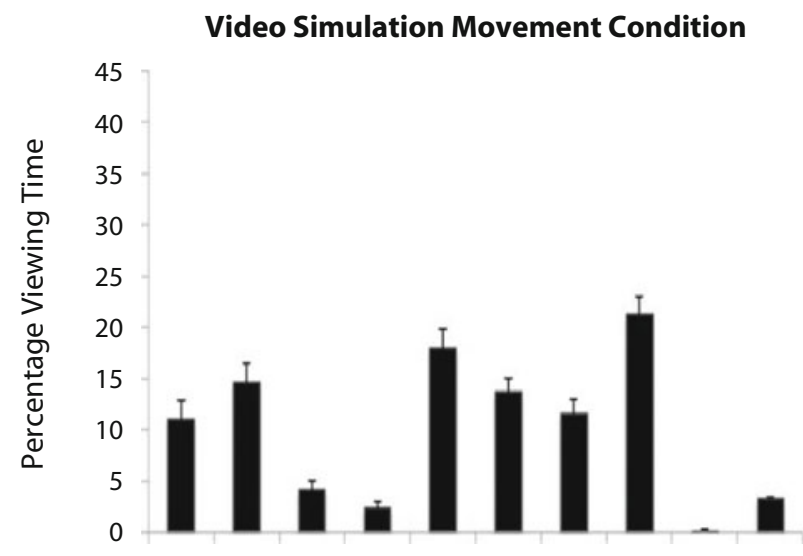

Head Torso UKL UNKL LKL LNKL F-B Ball Turf Other Location
In Situ Verbal Condition

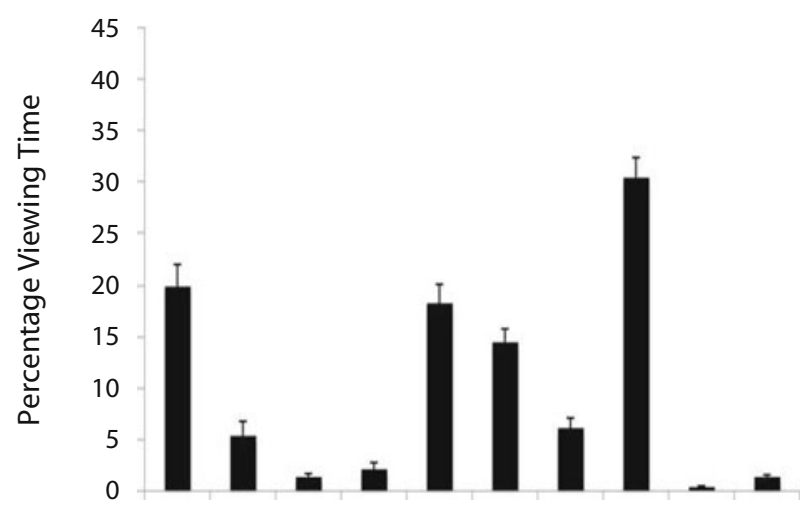

Head Torso UKL UNKL LKL LNKL F-B Ball Turf Other Location

In Situ Movement Condition

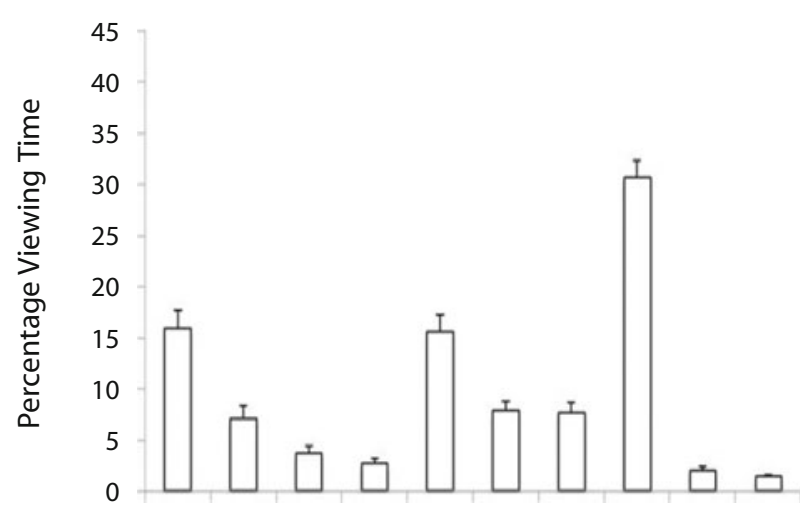

Head Torso UKL UNKL LKL LNKL F-B Ball Turf Other Location

In Situ Interception Condition

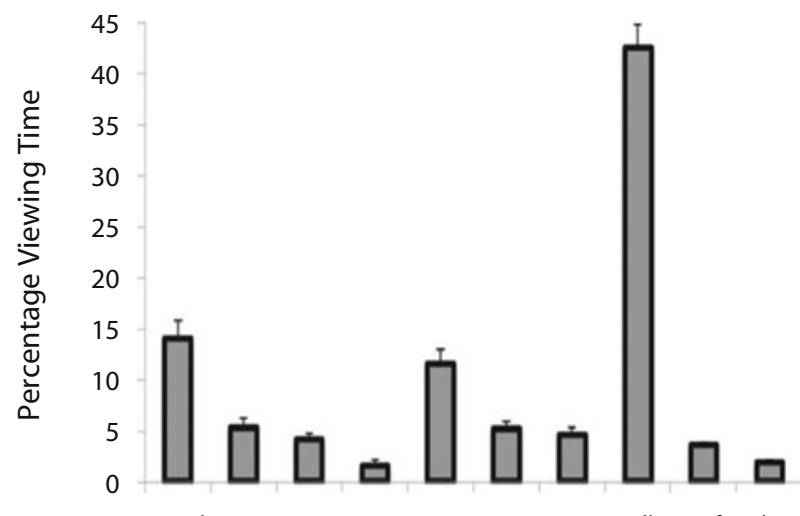

Head Torso UKL UNKL LKL LNKL F-B Ball Turf Other

Figure 5. Mean percentage time spent viewing each location during the total duration of the penalty kick across conditions. Torso, upper body (including arms); UKL, upper kicking leg and hip; UNKL, upper nonkicking leg and hip; LKL, lower kicking leg (including foot); LNKL, lower nonkicking leg (including foot); F-B, turf between the player and ball; turf, the turf in front of the ball. The vertical bars indicate the standard errors of the means. 


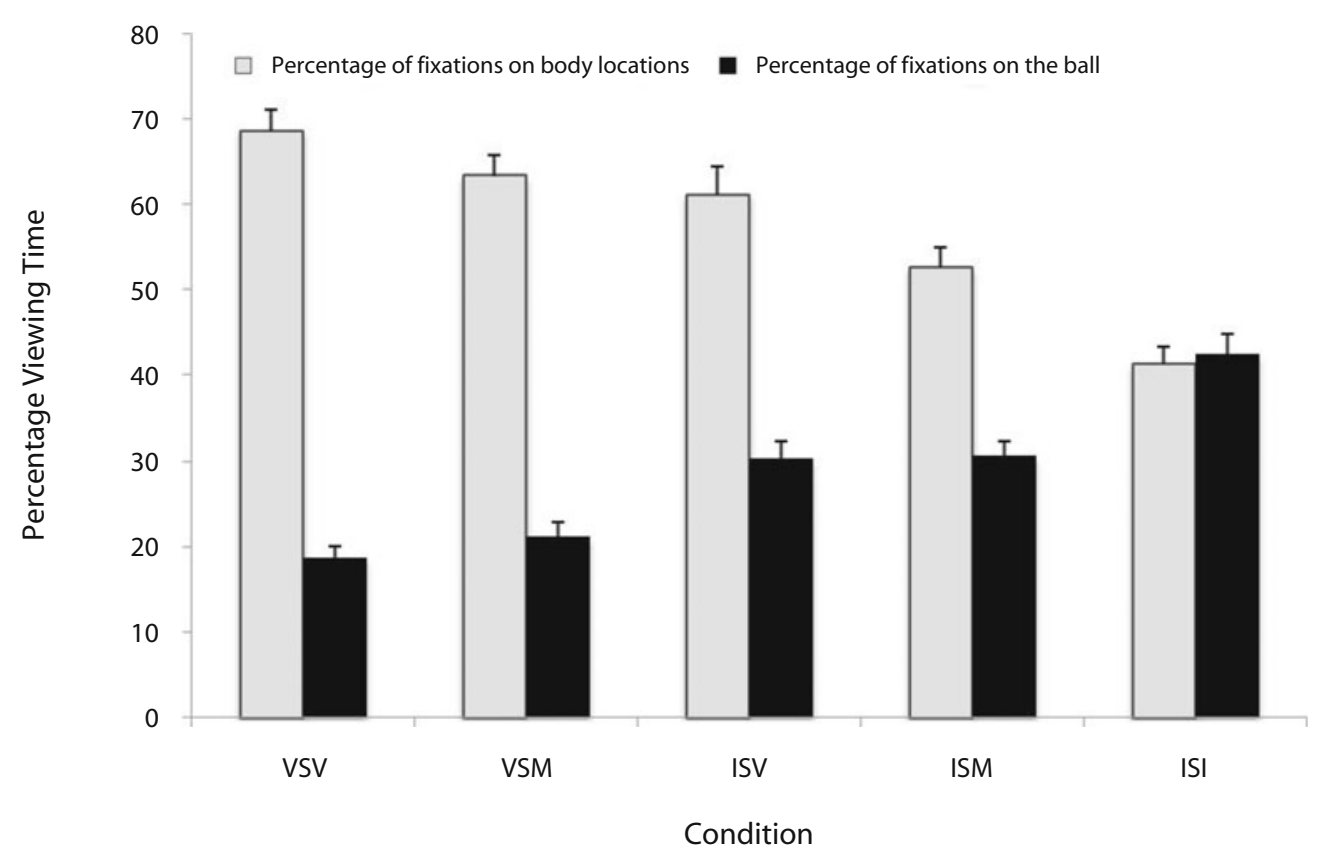

\begin{abstract}
Figure 6. Cumulative mean percentage time spent viewing anatomical locations in comparison with the ball across experimental conditions. The vertical bars indicate the standard errors of the means. VSV, video simulation verbal; VSM, video simulation movement; ISV, in situ verbal; ISM, in situ movement; ISI, in situ interception.
\end{abstract}

$1,500-1,001$ msec before contact in the ISM condition, the frequency with which gaze was directed toward this location was considerably less than in the ISI condition.

Figure 5 shows the percentage of time spent viewing each location during the duration of the whole run-up for each condition. As in previous research (e.g., Panchuk \& Vickers, 2006; Savelsbergh et al., 2005; Savelsbergh et al., 2002), the figure exemplifies that the most fixated locations included the head, torso, lower kicking leg, lower nonkicking leg, and ball, although there were pronounced differences among conditions. The goalkeepers spent comparable amounts of time fixating the ball and the sum of all anatomical locations during the ISI condition, whereas they spent more time fixating the kicker's anatomical locations relative to the ball for all other conditions (Figure 6).

A multivariate ANOVA revealed significant effects of condition [Wilk's $\Lambda=0.28, F(40,422)=4.108, p<.001$, $\left.\eta^{2}=.27\right]$ and time [Wilk's $\Lambda=0.11, F(30,326)=12.087$, $\left.p<.001, \eta^{2}=.52\right]$, and a condition $\times$ time interaction [Wilk's $\Lambda=0.14, F(120,876)=2.137, p<.001, \eta^{2}=$ .18]. Figure 7 illustrates how the percentage of fixations on the head, torso, lower kicking leg, lower nonkicking leg, and ball (i.e., the most frequently fixated locations across all conditions) changed over the duration of the penalty kick for each condition. Post hoc tests revealed that the participants spent more time fixating the torso in the VSM $(M=14.53 \%, S E=1.95)$ condition than in the ISV $(M=5.35 \%, S E=1.37)$, ISM $(M=7.02 \%$, $S E=1.35)$, and ISI $(M=5.16 \%, S E=1.12)$ conditions. They also fixated the lower nonkicking leg for longer in the VSV $(M=20.03 \%, S E=1.96)$ and ISV $(M=18.19$, $S E=1.83)$ conditions than in the ISI $(M=11.55 \%, S E=$ 1.39) condition, and they spent more time fixating the ball in the ISI $(M=42.48 \%, S E=2.31)$ condition than in any other condition (VSV, $M=18.77 \%, S E=1.28$; VSM, $M=21.17 \%, S E=1.79$; ISV, $M=30.38 \%, S E=1.67$; ISM, $M=30.61 \%, S E=1.67)$. There were no significant differences among conditions for time spent fixating the head or lower kicking leg.

The participants fixated the head for longer prior to and during the initial portion of the approach $(2,000-$ $1,501 \mathrm{msec}, M=31.18, S E=10.01)$ than in any other phase of the penalty kick $(1,500-1,001 \mathrm{msec}, M=19.88$, $S E=8.14 ; 1,000-501 \mathrm{msec}, M=6.65, S E=4.43 ; 500-$ $0+120 \mathrm{msec}$ after ball contact; $M=0.64, S E=0.58$ ). In contrast to that for the head, a very different search strategy was found for the ball. The participants fixated the ball longer in the final $500 \mathrm{msec}$ of the penalty kick $(500-0+120 \mathrm{msec}$ after contact; $M=59.78, S E=6.63)$ than in any other phase $(2,000-1,501 \mathrm{msec}, M=10.92$, $S E=3.11 ; 1,500-1,000 \mathrm{msec}, M=15.55, S E=4.29$; $1,000-501 \mathrm{msec}, M=30.76, S E=8.81)$.

The torso and lower kicking leg followed a similarly distributed pattern of gaze: These locations were fixated longer during the first $500 \mathrm{msec}(2,000-1,501 \mathrm{msec})$ of the approach (torso, $M=12.76, S E=3.88$; lower kicking leg, $M=20.72, S E=7.45$ ) than in the final $500 \mathrm{msec}$ of the penalty kick (torso, $M=0.90, S E=0.64$; lower kicking leg, $M=8.36, S E=2.17$ ). In addition, the torso was also fixated longer at 1,500-1,001 msec before ball $\operatorname{contact}(M=13.04, S E=4.75)$ than in the final $500 \mathrm{msec}$ 


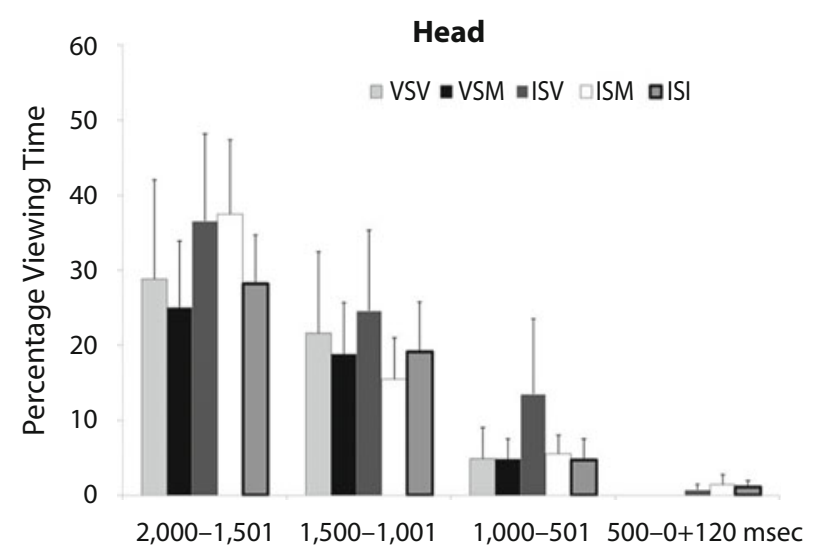

Phase of the Penalty Kick (msec)
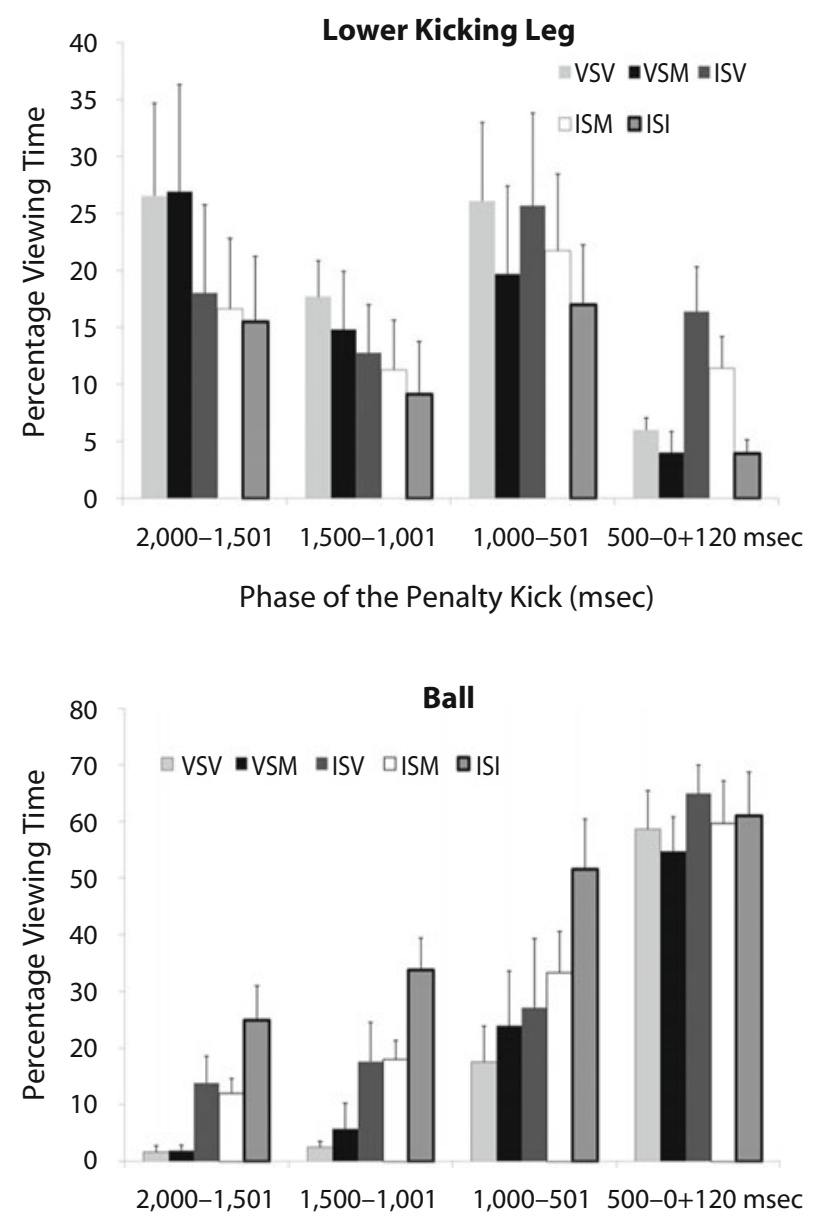

Phase of the Penalty Kick (msec)
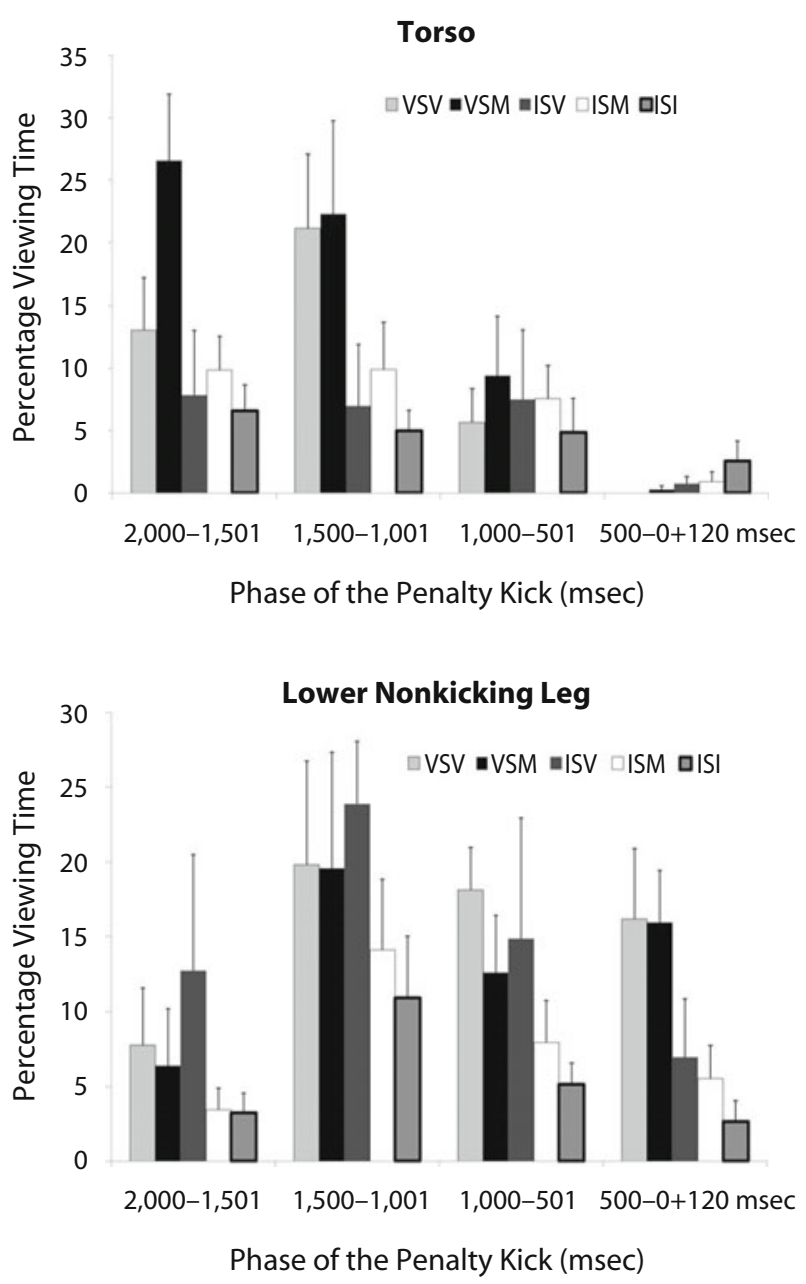

Figure 7. Mean percentage time spent viewing the head, torso, lower kicking leg, lower nonkicking leg, and ball across the four phases of the penalty kick. The vertical bars indicate the standard errors. VSV, video simulation verbal condition; VSM, video simulation movement condition; ISV, in situ verbal condition; ISM, in situ movement condition; ISI, in situ interception condition.

of the kick, whereas the lower kicking leg was fixated longer at $1,000-501 \mathrm{msec}$ before ball contact $(M=22.04$, $S E=6.92)$ than in the final $500 \mathrm{msec}$ of the kicking action. Finally, the nonkicking leg was fixated longer 1,500-
1,001 msec before ball contact $(M=17.66, S E=5.99)$ than in the first $500 \mathrm{msec}$ of the approach $(M=6.72$, $S E=3.81)$ and in the final $500 \mathrm{msec}$ of the run-up $(M=$ $9.45, S E=2.75$ ). 


\section{DISCUSSION}

A commonly expressed concern across research disciplines in psychology is that laboratory tasks may fail to adequately sample the environmental characteristics of many behavioral settings (e.g., Dhami et al., 2004; Hogarth \& Kareláia, 2007; van der Kamp et al., 2008). To study this issue in the performance environment of sports, in the present investigation, we set out to compare the gaze and movement behaviors of association football goalkeepers under two video simulation conditions (i.e., VSV and VSM) and three in situ conditions (i.e., ISV, ISM, and ISI). We attempted to ascertain whether existing findings derived from video and in situ studies that have implemented verbal and simulated movement measures are generalizable to in situ interception conditions that more closely represent the task constraints of everyday sports performance environments.

The study provided clear evidence demonstrating differences in the pattern of gaze for the distinct experimental task constraints. The most pronounced difference was that the goalkeepers fixated earlier and for a longer duration on the ball location in the ISI condition than in any other condition (Figures 4, 5, 6, and 7). In this regard, the pattern of gaze reported for the ISI condition is comparable with those in previous in situ studies of perceptual expertise (for a review, see Vickers, 2007). As in previous video simulation studies of the penalty kick (e.g., Savelsbergh et al., 2005; Savelsbergh et al., 2002), the most frequently fixated anatomical locations of the penalty taker in the present study included the head, torso, lower kicking leg and lower nonkicking leg (Figure 5). This finding was consistent across all experimental conditions, although, as with the ball location, there were differences among conditions. Gaze was most commonly directed toward the head or torso during the first $500 \mathrm{msec}$ of the approach in all conditions. As the penalty taker run-up evolved, there was an increased frequency of gaze fixations on the kicking and nonkicking legs for all conditions except ISI. For the VSV, VSM, and ISV conditions, gaze alternated between these locations until the final $500 \mathrm{msec}$ of the run-up, when the ball became the most commonly fixated location. The ball was the most frequently fixated location earlier in the ISM condition, 1,000-501 msec before ball contact. This finding suggests that the gaze pattern for the ISM condition may be an intermediate between the vision-for-perception-oriented conditions (i.e., VSV, VSM, and ISV) and the ISI condition, which requires vision for action.

Evidence from the present study indicates that the ambiguous findings from current gaze behavior studies may be reconciled by the distinct functional demands placed on vision for perception and action under the respective task constraints studied. The goal of participants in video simulation laboratory conditions is to perceptually judge the intentions of opponents on the test film, a task that requires vision for perception. Video simulation studies predicate the pickup of information that is external to the observer and independent of his or her position (i.e., allocentric; Klatzky, 1998; van der Kamp et al., 2008) in order to perceive the intentions of an opponent. Whether performance is measured through a verbal response (e.g., Abernethy, 1990), a buttonpress (e.g., Sebanz \& Shiffrar, 2009), a written response (e.g., Williams \& Burwitz, 1993), a joystick movement (e.g., Savelsbergh et al., 2002), or a simplified body movement (e.g., Jackson et al., 2006), participants are required to make perceptual judgments under these task constraints. The participants are not required to direct their gaze to pick up information that underpins the prospective control of movement, as is required when intercepting a moving projectile (e.g., see Oudejans et al., 1996; van der Kamp, Savelsbergh, \& Smeets, 1997).

In comparison with judgment conditions, the present study showed that biological motion information sources were fixated for less time when the task goal of a participant is not only to perceive the intentions of an opponent, but also to coordinate actions such as intercepting a projectile kicked by another individual. The participants spent a comparable amount of time gazing at the ball and kinematic information locations revealed during the penalty taker's motion. Therefore, the data indicate that empiricists may be incorrect to assume understanding of the visual information used by athletes in sports performance environments when assessing behavior with video simulation tasks in laboratories (see van der Kamp et al., 2008). These findings require replication and verification across other sports environments, using a greater continuum of participant skill levels, but they do question the suitability of video simulation laboratory tasks for studying perceptual expertise. Specifically, if the goal of empirical investigation is to record the information used by athletes to guide visual perception and action, video simulation conditions may be insufficient. If the aim of empiricists is solely to understand the (allocentric) information used by athletes for perception, video simulation tasks may provide a worthwhile experimental tool. However, the merit of such experimentation clearly has to be considered when the empirical evidence presented here is reflected on in conjunction with recent theoretical (Milner \& Goodale, 1995; van der Kamp et al., 2008) and experimental (e.g., Panchuk \& Vickers, 2006; Vickers, 2007) advances.

Specific to the above point, of particular interest in the present findings is the similarity of these results with recent gaze data reported by van Doorn et al. (2009). In response to presentations of the Müller-Lyer illusion, participants in the study of van Doorn et al. (2009) spent more time gazing at egocentric information (i.e., the illusion shaft) during grasping than manual estimation. van Doorn et al. (2009) concluded that the functional demands of task constraints on perception and action implicate differences in information pickup before any further processing by the ventral and dorsal streams. Similarly, data from our study suggest that the task constraints used to examine perceptual expertise may offer understanding about the contrasting sources of information pickup required for perceptual judgments (i.e., VSV, VSM, ISV, and ISM) and responses predicated on complementary perception and action (i.e., ISI). As the goalkeepers fixated on both the ball and anatomical locations in the ISI condition, it 
is plausible that the initial pickup of biological motion information (i.e., allocentric vision for perception) places a boundary constraint on vision for action in perceptualmotor tasks (Dijkerman, McIntosh, Schindler, Nijboer, \& Milner, 2009; van der Kamp, van Doorn, \& Masters, 2009; van Doorn, van der Kamp, \& Savelsbergh, 2007). Indeed, experimental conditions in which participants are required to utilize complementary visual information for perception and action are likely to be most informative about the integrated function of the dorsal and ventral pathways (Dewar \& Carey, 2006; Milner \& Goodale, 2008).

The pattern of gaze data discussed is supported by data showing that goalkeepers fixated on fewer different information locations in the ISI condition than in the VSV and VSM conditions (Figure 3). There were no differences among conditions for the number of fixations or mean fixation duration, with the exception of the longer fixation duration in the ISV condition than the ISM condition. The reason for the latter finding is not clear. One possibility is that there was an altered function of the vestibular-ocular system between ISV and ISM task constraints due to the use of the chinrest to restrict participant movement in the verbal response conditions, an issue that can be investigated further. There have been few attempts to examine the vestibular-ocular system in sports environments (Williams, Davids, \& Williams, 1999), but given the portability of eye movement recorders in recent times, this interpretation needs verifying in future research.

Goalkeepers made more saves in the ISM and ISI conditions than in the VSV and VSM conditions (see also Shim et al., 2005). However, the number of saves made across all conditions was greater than those typically observed during competition (see Savelsbergh et al., 2005). Interestingly, when compared with previous research, the response accuracies reported in the present investigation are both supported (Williams \& Burwitz, 1993) and contrasted (Savelsbergh et al., 2005). In the present study, the high performance levels may be a reflection of our decision to utilize a hybrid experimental design (Dhami et al., 2004). Such an approach was favored in order to ensure that we could attribute differences in goalkeepers' behavior to the functional requirements of vision for perception and action between experimental conditions. That is, we incorporated rudiments of systematic design into the experimental procedures, including instructions for the penalty taker to use a nondeceptive penalty kick strategy and to direct kicks toward predefined goal locations, with the aim of regulating the variability in their kicking action within and across conditions (see Schorer et al., 2007). Therefore, despite increased performance accuracy in the ISM and ISI conditions in comparison with the VSV and VSM conditions, further work is needed in order to ascertain whether these findings would have been different had we included deceptive trials in the experimental protocol. Indeed, the contrasting performance accuracy reported between the present study and Savelsbergh et al. (2005) may be reconciled by this factor, because penalty takers in the latter investigation were instructed to use deceptive penalty kick strategies. Despite recent advances (e.g., Cañal-Bruland \& Schmidt, 2009; Jackson et al., 2006), comparison of an opponent's deceptive and nondeceptive intent on sports performance has received sparse empirical attention in comparison with other psychology disciplines, such as judicial contexts (e.g., Bradford \& Goodman-Delahunty, 2008).

The findings of the present study highlight that a pressing issue in the perceptual expertise literature concerns appropriate sampling of environmental conditions in experimental designs. For example, it has been shown that performance variability is an inherent feature of the actions of athletes in sports environments (Davids et al., 2006). Attempts to control functional hallmarks of behavior in research designs (for example, by recording participant expertise with a buttonpress measure) may compromise inherent features of skilled performance. This is particularly pertinent considering the contemporary technological advances (e.g., Mobile Eye technology and three-dimensional motion-tracking systems) that have provided a viable alternative to traditional perceptual judgment tasks in laboratory studies of perceptual expertise. In order for empiricists to study sports performance, experimental conditions should offer participants opportunities for action that more closely represent the functional behaviors that define an athlete's expertise.

A supplementary issue to the implementation of a representative design concerns the analysis methods used to study perceptual expertise. To enable us to compare findings with previous research, we favored traditional analysis methods for the pattern of gaze (i.e., averaging data across trials and participants). However, such an approach tends to be predicated on the emphasis of an optimal or universal perceptual strategy used by all participants (Withagen $\&$ Chemero, 2009). This assumption has been questioned by observations of within-groups differences in gaze behaviors revealed between successful and less successful athletes with the same level of performance experience (Savelsbergh et al., 2005). The tendency to average data in statistical analyses may have masked important individual differences in performance (Newell, Liu, \& Mayer-Kress, 2001; Withagen \& Chemero, 2009). In future research, it might be more illuminating to consider the gaze behaviors of athletes at an individual level of analysis in order to understand the complex interaction of perception, cognition, and action capabilities that each individual exploits during everyday behavior in complex environments (for comparable approaches in the movement and perceptual learning literature, see Liu, Mayer-Kress, \& Newell, 2006; Withagen \& van Mermeskerken, 2009).

Finally, a particularly important implication for future research arising from the present study concerns the effectiveness of video-based perceptual training systems. The gaze behavior findings derived from video simulation laboratory tasks have traditionally underpinned the content of instruction protocols used in experimental paradigms aimed at training perceptual skills (e.g., Smeeton, Williams, Hodges, \& Ward, 2005; Williams et al., 2002). Such experimental bias may explain why the efficacy and transfer of existing perceptual training methodologies re- 
main relatively inconclusive. It is likely that video training environments facilitate the acquisition of judgment skills that are predicated on the pickup of information for perception, rather than the complementary pickup of ventral vision-for-perception and dorsal vision-for-action information sources utilized during sports performance. Furthermore, comparable limitations may also undermine the utilization of immersive virtual reality environments that fail to offer participants representative opportunities for action (see Craig et al., 2009).

\section{AUTHOR NOTE}

This article was written while the first author was supported by the University of Otago Postgraduate Scholarship Award. We are grateful to Nigel Barrett and Gavin Kennedy for providing assistance during the preparation of the experimental materials and the latter for invaluable assistance with development of data analysis software. We also thank the staff of the New Zealand Academy of Sport, South Island, and Otago Rugby for providing access to their training facility and to all participants for their cooperation and involvement in the study. Finally, Joan Vickers and three other anonymous reviewers are acknowledged for their valuable comments on an earlier version of the manuscript. Correspondence concerning this article should be addressed to M. Dicks, Institute of Cognitive and Team/Racket Sport Research, German Sport University Cologne, Am Sportpark Müngersdorf 6, 50933 Cologne, Germany (e-mail: m.dicks@dshs-koeln.de)

\section{REFERENCES}

Abernethy, B. (1990). Expertise, visual search, and information pickup in squash. Perception, 19, 63-77.

AraúJo, D., Davids, K., \& Passos, P. (2007). Ecological validity, representative design, and correspondence between experimental task constraints and behavioral setting: Comment on Rogers, Kadar, and Costall (2005). Ecological Psychology, 19, 69-78.

BaAyen, R. H., Davidson, D. J., \& Bates, D. M. (2008). Mixedeffects modeling with crossed random effects for subjects and items. Journal of Memory \& Language, 59, 390-412. doi:10.1016/j.jml .2007.12.005

Bagiella, E., Sloan, R. P., \& Heituan, D. F. (2000). Mixed-effects models in psychophysiology. Psychophysiology, 37, 13-20.

BradFord, D., \& GoODMAN-Delahunty, J. (2008). Detecting deception in police investigations: Implications for false confessions. Psychiatry, Psychology \& Law, 15, 105-118. doi:10.1080/13218710701873932

BRUNSWIK, E. (1955). Representative design and probabilistic theory in a functional psychology. Psychological Review, 62, 193-217.

BRUNSWIK, E. (1956). Perception and the representative design of psychological experiments (2nd ed.). Berkeley: University of California Press.

Burton, P., Gurrin, L., \& SLy, P. (1998). Extending the simple linear regression model to account for correlated responses: An introduction to generalized estimating equations and multi-level mixed modeling. Statistics in Medicine, 17, 1261-1291.

CaÑal-Bruland, R., \& Schmidt, M. (2009). Response bias in judging deceptive movements. Acta Psychologica, 130, 235-240. doi:10.1016/ j.actpsy.2008.12.009

Craig, C. M., Goulon, C., Berton, E., Rao, G., Fernandez, L., \& Bootsma, R. J. (2009). Optic variables used to judge future ball arrival position in expert and novice soccer players. Attention, Perception \& Psychophysics, 71, 515-522. doi:10.3758/APP.71.3.515

Davids, K., Button, C., Araújo, D., Renshaw, I., \& Hristovski, R. (2006). Movement models from sports provide representative task constraints for studying adaptive behavior in human movement systems. Adaptive Behavior, 14, 73-95.

Dewar, M. T., \& CAREY, D. P. (2006). Visuomotor immunity to perceptual illusion: A mismatch of attentional demands cannot explain the perception-action dissociation. Neuropsychologia, 44, 1501-1508. doi:10.1016/j.neuropsychologia.2005.11.010

Dhami, M. K., Hertwig, R., \& Hoffrage, U. (2004). The role of repre- sentative design in an ecological approach to cognition. Psychological Bulletin, 130, 959-988. doi:10.1037/0033-2909.130.6.959

Dijkerman, H. C., McIntosh, R. D., Schindler, I., NiJboer, T. C. W., \& Milner, A. D. (2009). Choosing between alternative wrist postures: Action planning needs perception. Neuropsychologia, 47, 14761482. doi:10.1016/j.neuropsychologia.2008.12.002

Dixon, P. (2008). Models of accuracy in repeated-measures designs. Journal of Memory \& Language, 59, 447-456. doi:10.1016/j.jml .2007.11.004

Dunwoody, P. T. (2006). The neglect of the environment by cognitive psychology. Journal of Theoretical \& Philosophical Psychology, 26, 139-153.

Farrow, D., \& Abernethy, B. (2003). Do expertise and the degree of perception-action coupling affect natural anticipatory performance? Perception, 32, 1127-1139. doi:10.1068/p3323

Fasolo, B., Hertwig, R., Huber, M., \& Ludwig, M. (2009). Size, entropy, and density: What is the difference between small and large real-world assortments? Psychology \& Marketing, 26, 254-279. doi:10 $.1002 /$ mar.20272

FIELD, A. (2009). Discovering statistics using SPSS (3rd ed.). London: Sage.

Gibson, J. J. (1979). The ecological approach to visual perception. Boston: Houghton Mifflin.

Hammond, K. R., \& Stewart, T. R. (2001). The essential Brunswik: Beginnings, explications, applications. Oxford: Oxford University Press.

Hogarth, R. M., \& Kareláia, N. (2007). Heuristic and linear models of judgment: Matching rules and environments. Psychological Review, 114, 733-758. doi: 10.1037/0033-295X.114.3.733

Huys, R., Smeeton, N. J., Hodges, N. J., Beek, P. J., \& Williams, A. M. (2008). On the dynamic information underlying visual anticipation skill. Perception \& Psychophysics, 70, 1217-1234. doi:10.3758/ PP.70.7.1217

JaCKSON, R. C., Warren, S., \& Abernethy, B. (2006). Anticipation skill and susceptibility to deceptive movement. Acta Psychologica, 123, 355-371. doi:10.1016/j.actpsy.2006.02.002

Kareláia, N., \& Hogarth, R. M. (2008). Determinants of linear judgment: A meta-analysis of lens model studies. Psychological Bulletin, 134, 404-426. doi:10.1037/0033-2909.134.3.404

Kellis, E., \& Katis, A. (2007). Biomechanical characteristics and determinants of instep soccer kick. Journal of Sports Science \& Medicine, 6, 154-165.

KLATZKY, R. L. (1998). Allocentric and egocentric spatial representations: Definitions, distinctions, and interconnections. In C. Freksa, C. Habel, \& K. F. Wender (Eds.), Spatial cognition: An interdisciplinary approach to representation and processing of spatial knowledge (pp. 1-17). Berlin: Springer.

Kliegl, R., Risse, S., \& Laubrock, J. (2007). Preview benefit and parafoveal-on-foveal effects from word $n+2$. Journal of Experimental Psychology: Human Perception \& Performance, 33, 1250-1255. doi:10.1037/0096-1523.33.5.1250

Liu, Y.-T., Mayer-Kress, G., \& Newell, K. M. (2006). Qualitative and quantitative change in the dynamics of motor learning. Journal of Experimental Psychology: Human Perception \& Performance, 32, 380-393. doi:10.1037/0096-1523.32.2.380

ManN, D. T. Y., Williams, A. M., Ward, P., \& Janelle, C. M. (2007). Perceptual cognitive expertise in sport: A meta-analysis. Journal of Sport \& Exercise Psychology, 29, 457-478.

McPherson, S. L., \& Vickers, J. N. (2004). Cognitive control in motor expertise. International Journal of Sport \& Exercise Psychology, 2, 274-300.

Michaels, C. F. (2000). Information, perception, and action: What should ecological psychologists learn from Milner and Goodale (1995)? Ecological Psychology, 12, 241-258.

Michaels, C. F., \& Carello, C. (1981). Direct perception. Englewood Cliffs, NJ: Prentice Hall.

Milner, A. D., \& Goodale, M. A. (1995). The visual brain in action. Oxford: Oxford University Press.

Milner, A. D., \& Goodale, M. A. (2008). Two visual systems re-viewed. Neuropsychologia, 46, 774-785. doi:10.1016/j.neuropsychologia .2007 .10 .005

Morya, E., Bigatão, H., Lees, A., \& Ranvaud, R. (2005). Evolving 
penalty kick strategies: World Cup and club matches 2000-2002. In T. Reilly, J. Cabri, \& D. Araújo (Eds.), Science and football (Vol. 5, pp. 237-242). London: Taylor \& Francis.

Müller, S., Abernethy, B., \& Farrow, D. (2006). How do worldclass cricket batsmen anticipate a bowler's intention? Quarterly Journal of Experimental Psychology, 59, 2162-2186. doi:10.1080/ 02643290600576595

Müller, S., Abernethy, B., Reece, J., Rose, M., Eid, M., McBEAN, R., ET AL. (2009). An in-situ examination of the timing of information pick-up for interception by cricket batsmen of different skill levels. Psychology of Sport \& Exercise, 10, 644-652. doi:10.1016/ j.psychsport.2009.04.002

Newell, K. M., Liu, Y. T., \& MaYer-Kress, G. (2001). Time scales in motor learning and development. Psychological Review, 108, 57-82. doi:10.1037//0033-295X.108.1.57

Oudejans, R. R. D., Michaels, C. F., Bakker, F. C., \& Dolné, M. A. (1996). The relevance of action in perceiving affordances: Perception of catchableness of fly balls. Journal of Experimental Psychology: Human Perception \& Performance, 22, 879-891.

PanchuK, D., \& Vickers, J. N. (2006). Gaze behaviors of goaltenders under spatial-temporal constraints. Human Movement Science, 25 , 733-752. doi:10.1016/j.humov.2006.07.001

Rowe, R., Horswill, M. S., Kronvall-Parkinson, M., Poulter, D. R., \& McKenna, F. P. (2009). The effect of disguise on novice and expert tennis players' anticipation ability. Journal of Applied Sport Psychology, 21, 178-185. doi:10.1080/10413200902785811

Savelsbergh, G. J. P., van der Kamp, J., Williams, A. M., \& WARD, P. (2005). Anticipation and visual search behavior in expert soccer goalkeepers. Ergonomics, 48, 1686-1697. doi:10.1080/ 00140130500101346

Savelsbergh, G. J. P., Willliams, A. M., van der Kamp, J., \& Ward, P. (2002). Visual search, anticipation and expertise in soccer goalkeepers. Journal of Sports Sciences, 20, 279-287.

Schorer, J., BaKer, J., FAth, F., \& JaITNER, T. (2007). Identification of interindividual and intraindividual movement patterns in handball players of varying expertise levels. Journal of Motor Behavior, 39, 409-421.

Sebanz, N., \& Shiffrar, M. (2009). Detecting deception in a bluffing body: The role of expertise. Psychonomic Bulletin \& Review, 16, 170175. doi: 10.3758/PBR.16.1.170

Shim, J., Carlton, L. G., Chow, J. W., \& Chae, W. K. (2005). The use of anticipatory visual cues by highly skilled tennis players. Journal of Motor Behavior, 37, 164-175.

Singer, R. N., Cauraugh, J. H., Chen, D., Steinberg, G. M., \& FrehLICH, S. G. (1996). Visual search, anticipation, and reactive comparisons between highly skilled and beginning tennis players. Journal of Applied Sport Psychology, 8, 9-26.

Smeeton, N. J., Williams, A. M., Hodges, N. J., \& Ward, P. (2005). The relative effectiveness of various instructional approaches in developing anticipation skill. Journal of Experimental Psychology: Applied, 11, 98-110. doi:10.1037/1076-898X.11.2.98

VAN DER KAMP, J. (2006). A field simulation study of the effectiveness of penalty kick strategies in soccer: Late alterations of kick direction increase errors and reduce accuracy. Journal of Sports Sciences, 24, 467-477. doi:10.1080/02640410500190841

van Der Kamp, J., Oudejans, R. R. D., \& SAVelsbergh, G. J. P. (2003). The development and learning of the visual control of movement: An ecological perspective. Infant Behavior \& Development, 26, 495-515. doi:10.1016/j.infbeh.2003.09.002

van der Kamp, J., Rivas, F., van Doorn, H., \& Savelsbergh, G. J. P.
(2008). Ventral and dorsal contributions in visual anticipation in fast ball sports. International Journal of Sport Psychology, 39, 100-130.

van Der Kamp, J., Savelsbergh, G. J. P., \& Smeets, J. (1997). Multiple information sources in interceptive timing. Human Movement Science, 16, 787-821.

van Der Kamp, J., van Doorn, H., \& Masters, R. S. W. (2009). A Judd illusion in far-aiming: Evidence of a contribution to action by vision for perception. Experimental Brain Research, 197, 199-204. doi:10.1007/s00221-009-1889-z

Van Dongen, H. P., Caldwell, J. A., JR., \& Caldwell, J. L. (2006). Investigating systematic individual differences in sleep-deprived performance on a high-fidelity flight simulator. Behavior Research Methods, 38, 333-343.

van Doorn, H., van der Kamp, J., De Wit, M., \& Savelsbergh, G. J. P. (2009). Another look at the Müller-Lyer illusion: Different gaze patterns in vision for action and perception. Neuropsychologia, 47, 804-812. doi:10.1016/j.neuropsychologia.2008.12.003

van Doorn, H., van Der Kamp, J., \& SAVElsbergh, G. J. P. (2007). Grasping the Müller-Lyer illusion: The contributions of vision for perception and vision for action. Neuropsychologia, 45, 1939-1947. doi:10.1016/j.neuropsychologia.2006.11.008

Vicente, K. J. (2003). Beyond the lens model and direct perception: Toward a broader ecological psychology. Ecological Psychology, 15, 241-267.

VICKERS, J. N. (1996). Visual control when aiming at a far target. Journal of Experimental Psychology: Human Perception \& Performance, 22, 342-354.

VICKERS, J. N. (2007). Perception, cognition, and decision training: The quiet eye in action. Champaign, Il: Human Kinetics.

WARREN, W. H., JR. (1984). Perceiving affordances: Visual guidance of stair climbing. Journal of Experimental Psychology: Human Perception \& Performance, 10, 683-703.

WARREN, W. H.[, JR.] (2006). The dynamics of perception and action. Psychological Review, 113, 358-389. doi:10.1037/0033 $-295 X .113 .2 .358$

Wigton, R. S. (2008). What do the theories of Egon Brunswik have to say to medical education? Advances in Health Sciences Education, 13, 109-121. doi:10.1007/s10459-006-9023-5

Williams, A. M., \& Burwitz, L. (1993). Advance cue utilization in soccer. In T. Reilly, J. Clarys, \& A. Stibbe (Eds.), Science and football (Vol. 2, pp. 239-244). London: Spon.

Williams, A. M., Davids, K., \& Williams, J. G. (1999). Visual perception and action in sport. London: Spon.

WillLiams, A. M., \& GRIFFITHS, I. W. (2002). A kinematic analysis of the prevalence of pre-impact cues in the football penalty kick. Journal of Sports Sciences, 20, 74

Williams, A. M., Ward, P., Knowles, J. M., \& SMeeton, N. J. (2002). Anticipation skill in a real-world task: Measurement, training, and transfer in tennis. Journal of Experimental Psychology: Applied, 8, 259-270. doi:10.1037/1076-898X.8.4.259

Withagen, R., \& Chemero, A. (2009). Naturalizing perception: Developing the Gibsonian approach to perception along evolutionary lines. Theory \& Psychology, 19, 363-389. doi:10.1177/0959354309104159

Withagen, R., \& VAN MERMESKERKEN, M. (2009). Individual differences in learning to perceive length by dynamic touch: Evidence for variation in perceptual learning capacities. Attention, Perception, \& Psychophysics, 71, 64-75. doi:10.3758/APP.71.1.64

(Manuscript received September 13, 2009; revision accepted for publication November 6, 2009.) 